\title{
Brazilian Journal \\ of Chemical

\section{EFFECTS OF OPERATING CONDITIONS ON COMPOSITIONAL CHARACTERISTICS AND REACTION KINETICS OF LIQUID DERIVED BY DELAYED COKING OF NIGERIAN PETROLEUM RESIDUE}

\author{
O. O. Bello ${ }^{1 *}$, B. T. Ademodi ${ }^{1}$, S. R. A. Macaulay ${ }^{1}$ and G. K. Latinwo ${ }^{2}$ \\ ${ }^{1}$ Department of Chemical Engineering, Obafemi Awolowo University, Ile-Ife, Nigeria. \\ ${ }^{1}$ Institute of Petroleum Engineering, Technische Universität Clausthal, \\ Fax: +(49) 5323 72-3146, Agricolastraße 10, 38678 Clausthal-Zellerfeld, Germany \\ E-mail: oladele.bello@tu-clausthal.de \\ ${ }^{2}$ Department of Chemical Engineering, Ladoke Akintola University of Technology, \\ Ogbomoso, Nigeria.
}

(Received: May 10, 2005; Accepted : April 5, 2006)

\begin{abstract}
The thermal upgrading of Nigerian petroleum residue was studied at relatively low pressure in a delayed coking reactor system. In this work, the intent was to investigate the effects of process variables such as reaction temperature $\left(200^{\circ} \mathrm{C}\right.$ to $\left.600^{\circ} \mathrm{C}\right)$, reaction time (0 to $\left.120 \mathrm{~min}\right)$, additive concentration loading and additive-to-residue ratio on the amounts and quality of organic liquid product (OLP). The liquid products derived from the delayed coking process were characterized by means of instrumental analysis of gas-liquid chromatography. Results obtained from the analyses of the OLP revealed an upward trend of the conversion process and the selectivity of the aromatic compounds with additive-to-residue ratio (ARR) and increase in temperature. This led to maximum yield of $37.2 \%$ achieved with ARR of 5 compared to 31\% achieved with ordinary thermal conversion. The selectivity for aromatic hydrocarbons was maximum at $83.1 \mathrm{wt} \%$ the selectivity towards aromatics and aliphatic hydrocarbons were highest for methanol-potassium hydroxide and methanol respectively. In all additive system cases, maximum OLP was produced at an optimum reaction temperature of $370^{\circ} \mathrm{C}$ in the delayed coking reactor and at higher residence time. The gaseous product consisted of carbon monoxide and carbon dioxide and $\mathrm{C}_{1}-\mathrm{C}_{6}$ hydrocarbons, which amounted to about 20 to $30 \mathrm{wt} \%$ of liquid distillate. The information obtained in this study show that the organic liquid products are amenable to characterization procedure and provided the basis for the identification of processes for upgrading Nigerian petroleum residue and such other starting materials such as bitumen or fossil fuel coal liquids

Keywords: Petroleum residue; Delayed coking; Product distribution; Nigeria.
\end{abstract}

\section{INTRODUCTION}

There has been continued interest in the exploitation of the world's petroleum residues for reasons related to both economic and market forecasts as well as reasons of national interest to those countries in which the residues are generated and accumulated. The petroleum residue is a potential source of synthetic fuels and precious chemicals. In order to effectively use these petroleum residues, it is necessary that they be upgraded. Several alternatives are available to

*To whom correspondence should be addressed 
accomplish this upgrading. Catalytic upgrading of the residue is necessarily more expensive because of the higher catalyst and hydrogen consumptions. In general, some hydro-processing will be required to eventually produce finished products but the high investment and operating costs of hydro-processing can be mitigated by the introduction of non-catalytic processes to upgrade residues [Bello, et. al., 2001]. Among the upgrading processes, delayed coking is more important because of its low investing and operating costs, broad feed stock applicability and high conversion [Elliot, et. al., 1981]. Delayed coking is a severe form of thermal cracking in which the viscosity and pour point of the liquid hydrocarbon base material is permanently reduced after it has been subjected to severe temperature for a period of time at comparatively low pressure under inert condition.

Several investigators Jiazhi, et. al., 2002a; Zacheria, et. al., 1982; Bonila, 1982; Jiazhi, et. al., 2002b] have reported the results of deasphalting and thermal conversion of Athabasca oil sands, Arabian heavy crude, Orinoco heavy crude, Lloydminster heavy oil, Loda (Nigeria) tar sand and Marguerite lake bitumen as feedstock under variety of operating conditions. Since the petroleum residue characteristics vary drastically from one region to another, delayed coking application problems and solutions also vary. Process conditions that are effective in one system are not always successful in others because most applications are those developed for tar and oil sand bitumen and not from petroleum derived fluids or petroleum based fractions.
While the issue of delayed coking upgrading has been addressed by numerous studies [Bello, et. al., 2001; Ukwuoma, 1993; Elliot, et. al., 1981; Schucker, 1983; Zacheria, et. al., 1982; Bonila, 1982; Jiazhi, et. al., 2002b], information relating delayed coking product spectrum to Nigerian petroleum residue characteristics is not available. Such information could foster design concepts and optimization strategies for utilizing a vast accumulation of petroleum residues in all the nation's refineries. The present work tries to provide a better description of the conversion of Nigerian petroleum refinery residue to synthetic fuels and chemicals using delayed coking reactor system at various operating conditions. The effect of process variables such as temperatures, reaction time and chemical additives on the organic liquid product (OLP) yield and kinetics was studied.

\section{MATERIAL AND METHODS}

The vacuum residue of Nigerian medium gravity crude was used in this study. The physical properties of the residue are given in Table 1. Detailed procedures for characterizing the residue has been reported elsewhere [Bello, et. al., 2001].

The experimental aspects of the present study consist essentially of (a) thermal conversion of the residue with methanol-potassium hydroxide and methanol followed by (b) chromatographic analysis of the samples of the products obtained from the thermal upgrading experiments.

Table 1: Physical properties of Nigerian Petroleum Residue [Bello, et. al., 2001]

\begin{tabular}{|l|c|}
\hline \multicolumn{1}{|c|}{ Physical Properties } & Values \\
\hline Gravity, API & 11.9 \\
Viscosity, cS $\left(\mathrm{mm}^{2} / \mathrm{s}\right)$ at $100^{\circ} \mathrm{C}$ & 526.8 \\
Sulphur, wt. \% & 0.3 \\
Conradson carbon residue, wt. \% & 16.0 \\
Pour point, ${ }^{0} \mathrm{C}$ & 41.0 \\
Viscosity index & 131.1 \\
Viscosity gravity constant & 0.9 \\
Vanadium, ppm & 1.9 \\
Nickel, ppm & 15.0 \\
\hline
\end{tabular}

\section{Equipment and Experimental Procedure}

The thermal conversion of the petroleum residue was studied in a delayed coking reactor system with additive concentration and additive-to-residue ratio been varied. The system is comprised of the following components; reactor and transport, a trapping and analyzing. This reactor was used to thermally crack the petroleum residue, which was followed by upgrading with the additive systems. The reactor was made of 316 stainless steel tubing, $50 \mathrm{~mm}$ in internal diameter enclosed in a bigger cylindrical pipe of about $80 \mathrm{~mm}$ in outside diameter. The tubular vessel and its bigger enclosure were both 
held in place by a flange of $80 \mathrm{~mm}$ outside diameter with $19.1 \mathrm{~mm}$ thickness. The annulus consists of an electric heater capable of heating the feed sample to the desired temperature. Here, under precise temperature control, the desired sample cracking can be achieved. The carrier gas, which is nitrogen gas, transports the cracked sample to the shell and tube condenser. It has been demonstrated that the residence in the reactor does not vary by more than $\pm 10 \%$ [Jiazhi, et. al., 2002a]. The reactor is capable of being operated at temperatures of up to $600^{\circ} \mathrm{C}$ and at residence time of 0 to 120 minutes. The products of thermal conversion are cooled in a shell and tube condenser, collected, characterized and analyzed using analytical equipment. The schematic diagram of the experimental setup is shown in Figure 1.

The experimental runs were carried out at low pressure in a batch reaction system operated within the temperature range of $200-600^{\circ} \mathrm{C}$ and residence time of 30 to 120 minutes. In a typical run, the petroleum residue was fed into delayed coking reactor. Prior to delay cooking conversion process, the Nigerian refinery fuel oil was purged with nitrogen in the reactor for 10 minutes to remove residual oxygen. The Nigeria refinery fuel oil was heated at $800^{\circ} \mathrm{C} / \mathrm{s}$ to reaction temperatures between 100 and $600^{\circ} \mathrm{C}$ and maintained at that temperature for 30 to 120 minutes. Using a shell and tube condenser, the resulting gaseous product stream was condensed and colleted in a vessel. At the conclusion of each run, the yields were measured. For some experiments, the Nigerian residue samples charged into the reactor was dosed with varied amounts of methanol and alcoholic potassium hydroxide loading and additive-to-residue ratio. A T-shaped agitator was used to achieve proper mixing during reaction to ensure uniformity of reaction. The procedure was repeated for every 30 minutes, until the total residence time for each isothermal operation was 120 minutes. The gaseous product steam was passed through a condenser and the liquid product collected.

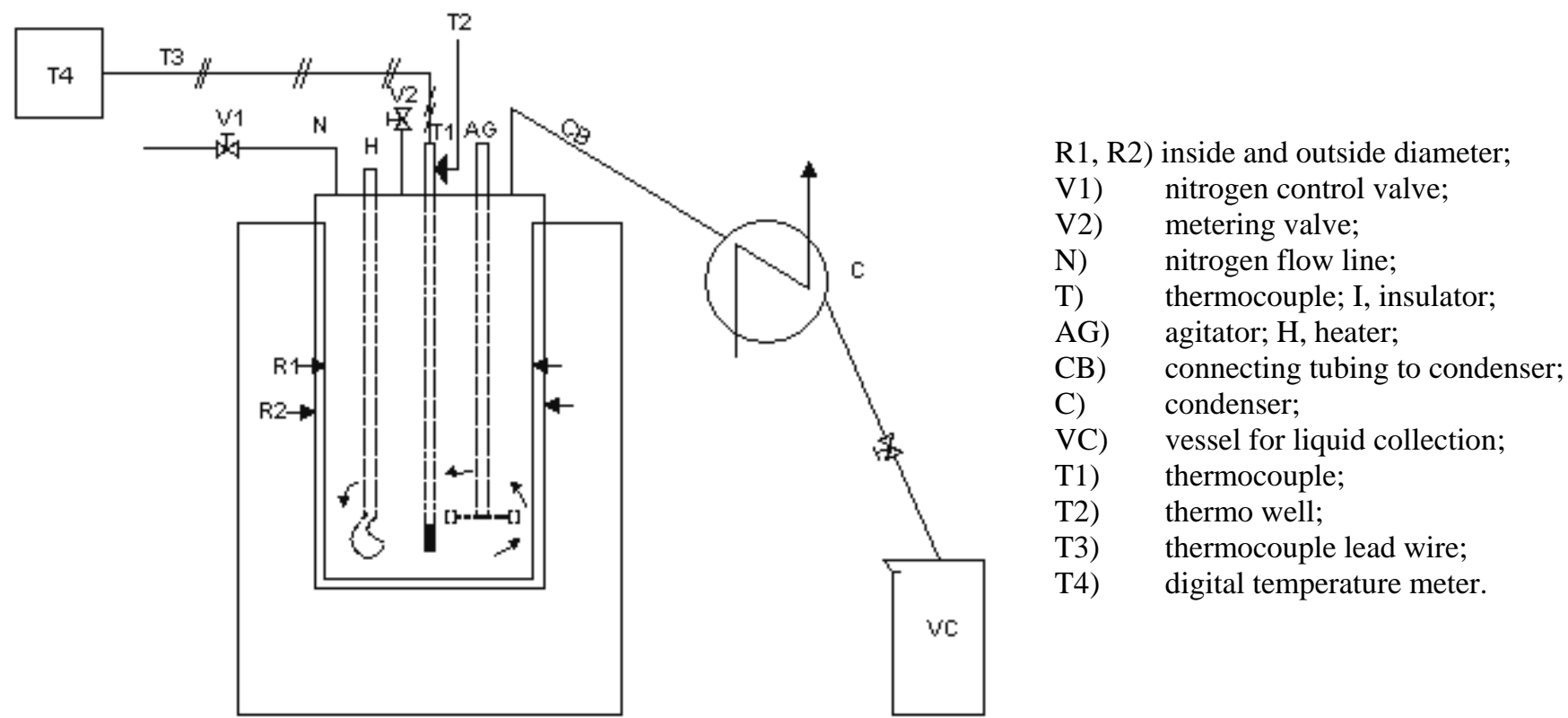

Figure 1: Schematic diagram of the experimental apparatus

\section{Product Analyses}

The liquid product had a single homogeneous phase, and a few of these product samples were distilled at $200^{\circ} \mathrm{C}$ and $172 \mathrm{~Pa}$ using a Buchi GKR56 distillation unit. No residue was observed after this distillation. This shows that substantial cracking of the non-volatile fraction of the petroleum residue had occurred during the upgrading process. Therefore, all other liquid products were directly analyzed by a gas chromatography (Carle GC-500) with a banded non-polar (methyl silicone) $50 \mathrm{~m}$ x $0.2 \mathrm{~mm}$ i.d. capillary column and a flame ionization detector (FID). The compounds present in the liquid product were identified by using standard compounds and by GC-MS (Finningan/MAT-4500). The total weight of each component class of the distillate was determined from the percentage of each component class in the total products collected. 
RESULTS AND DISCUSSION

\section{Thermal Upgrading of the Petroleum Refinery Fuel Oil in the Delayed Coking Reactor}

The petroleum residue samples were tested on the apparatus and delayed coking tests were performed for each petroleum residues at eight reaction temperatures $(250,300,350,450,500,550$, and $600^{\circ} \mathrm{C}$ ). The results reported here are averages of a minimum of four tests performed per petroleum residues at each reaction temperature. The product yields are listed in Table 2 . The product yields from tests performed at $400^{\circ} \mathrm{C}$ temperature were repeatable as illustrated by the standard deviation of the measured light oil given in Table 2. The standard deviation was between 0.2 and $4.0 \%$ and was generally less than $2.0 \%$. Approximately $0.5 \%$ of this variation may be due to the accuracy of the balance used to determine the yields.

Experiments were carried out also to study the characteristics of solid and liquid products obtained from eleven samples of petroleum residues with different properties (specific gravity, apparent viscosity, pour point, sulfur content, etc) were used as feed. Various physical characteristics of the liquid product obtained during the thermal treatment of petroleum residues are also presented in Tables 2 and 3. A comparison of the physical properties of whole petroleum residues and liquid product derived from thermal upgrading of petroleum residues shows that the viscosity and density of liquid product were lower than those of the original petroleum refinery fuel oil. Chemical composition of the liquid product obtained during thermal treatment of petroleum residues is presented in Table 4 . The liquid product consisted of $49.1 \mathrm{wt} \%$ aliphatic hydrocarbons, 23.5 wt $\%$ aromatic hydrocarbons, and 12.4 wt $\%$ naphthenic hydrocarbons, apart from minor fraction of phenols, ketones, alcohols, acids and esters. For a given treatment time, the two products yields increased with treatment temperature, the results are shown in Figures 2 and 3. The observed trend of the yield showed that increasing the treatment temperature and time might increase the yield of the two products.

Table 2: Methanol and Methanolic Potassium Hydroxide mixture Thermal conversion yields as a function of Temperature $\left(400^{\circ} \mathrm{C}\right)$ and Time $(120 \mathrm{~min})$

\begin{tabular}{|c|c|c|c|c|}
\hline \multirow[b]{2}{*}{ Solvent-to-residue ratio } & \multirow[b]{2}{*}{$\begin{array}{c}\text { Cracking } \\
\text { Temperature } \\
\left({ }^{0} \mathrm{C}\right) \\
\end{array}$} & \multirow[b]{2}{*}{$\begin{array}{c}\text { Treatment } \\
\text { Time (mins.) }\end{array}$} & \multicolumn{2}{|c|}{ Product Yield Percent } \\
\hline & & & $\begin{array}{l}\text { Light Oil Product } \\
\text { (wt.\%) }\end{array}$ & $\begin{array}{l}\text { Liquid condensate } \\
\text { (wt.\%) }\end{array}$ \\
\hline \multicolumn{5}{|l|}{ Methanol } \\
\hline 1 & 400 & 120 & 11.65 & 1.96 \\
\hline 2 & 400 & 120 & 15.63 & 2.50 \\
\hline 3 & 400 & 120 & 21.88 & 3.36 \\
\hline 4 & 400 & 120 & 27.20 & 4.23 \\
\hline 5 & 400 & 120 & 14.23 & 5.19 \\
\hline 6 & 400 & 120 & 17.08 & 6.70 \\
\hline 7 & 400 & 120 & 24.42 & 7.67 \\
\hline 8 & 400 & 120 & 31.75 & 8.88 \\
\hline \multicolumn{5}{|l|}{$\begin{array}{l}\text { Methanolic Potassium } \\
\text { Hydroxide Mixture }\end{array}$} \\
\hline 2 & 400 & 120 & 36.04 & 3.42 \\
\hline 4 & 400 & 120 & 54.11 & 5.16 \\
\hline 6 & 400 & 120 & 69.12 & 7.37 \\
\hline 8 & 400 & 120 & 86.70 & 8.33 \\
\hline 10 & 400 & 120 & 71.05 & 9.47 \\
\hline
\end{tabular}


Table 3: Change in the Viscosity, Density, API gravity and Pour Point of the derived liquid products from the Nigeria Petroleum Residue with Treatment.

Temperature and Time

\begin{tabular}{|c|c|c|c|c|c|c|}
\hline \multicolumn{3}{|c|}{ Treatment of the Product } & $\begin{array}{l}\text { Viscosity of the } \\
\text { product }\end{array}$ & $\begin{array}{l}\text { Density of } \\
\text { the product }\end{array}$ & $\begin{array}{c}\text { API gravity of the } \\
\text { product }\end{array}$ & $\begin{array}{c}\text { Pour point of the } \\
\text { product }\end{array}$ \\
\hline Run No. & $\begin{array}{c}\text { Temperature } \\
\left({ }^{0} \mathrm{C}\right)\end{array}$ & $\begin{array}{l}\text { Treatment time } \\
\text { (Mins.) }\end{array}$ & (сp.) & $\mathrm{gm} / \mathrm{cm}^{3}$ & ( ${ }^{0}$ API gravity) & $\left({ }^{0} \mathrm{C}\right)$ \\
\hline 1 & 100 & 30 & 51.28 & 0.936 & 19.70 & 24.3 \\
\hline 2 & 100 & 60 & 42.23 & 0.925 & 21.47 & 25.02 \\
\hline 3 & 100 & 90 & 39.56 & 0.910 & 24.00 & 26.15 \\
\hline 4 & 100 & 120 & 31.33 & 0.891 & 27.30 & 27.80 \\
\hline 5 & 200 & 30 & 29.33 & 0.862 & 32.65 & 28.19 \\
\hline 6 & 200 & 60 & 27.59 & 0.837 & 37.56 & 29.22 \\
\hline 7 & 200 & 90 & 25.83 & 0.818 & 41.48 & 30.54 \\
\hline 8 & 200 & 120 & 23.11 & 0.794 & 46.71 & 31.10 \\
\hline 9 & 300 & 30 & 21.84 & 0.786 & 48.50 & 32.35 \\
\hline 10 & 300 & 60 & 20.66 & 0.773 & 51.60 & 32.69 \\
\hline 11 & 300 & 90 & 18.18 & 0.764 & 53.71 & 33.11 \\
\hline 12 & 300 & 120 & 15.70 & 0.752 & 56.61 & 34.46 \\
\hline 13 & 400 & 30 & 12.40 & 0.744 & 58.69 & 35.36 \\
\hline 14 & 400 & 60 & 11.27 & 0.731 & 62.07 & 36.47 \\
\hline 15 & 400 & 90 & 10.43 & 0.725 & 63.70 & 38.12 \\
\hline 16 & 400 & 120 & 9.78 & 0.720 & 65.03 & 38.67 \\
\hline 17 & 500 & 30 & 8.73 & 0.703 & 69.78 & 39.41 \\
\hline 18 & 500 & 60 & 8.42 & 0.695 & 72.10 & 41.25 \\
\hline 19 & 500 & 90 & 8.10 & 0.689 & 73.87 & 41.80 \\
\hline 20 & 500 & 120 & 7.57 & 0.684 & 75.37 & 42.22 \\
\hline
\end{tabular}

Table 4: Chemical composition of the liquid product obtained from Thermal treatment of Nigerian Petroleum Residue

\begin{tabular}{|l|r|r|}
\hline Chemical composition & & wt\% \\
\hline Water & & 46.2 \\
Organic fraction & & 53.8 \\
Total & g & 100 \\
\hline Chemical composition of organic fraction & 17.6 & wt \% \\
\hline Aliphatic hydrocarbon & 0.5 & 39.0 \\
Benzene & 2.7 & 1.1 \\
Toluene & 0.9 & 6.0 \\
Xylene & 13.9 & 2.0 \\
Other cyclic hydrocarbons & 1.5 & 30.8 \\
Phenols & 0.3 & 3.3 \\
Alcohols & 0.2 & 0.7 \\
Ketones & 2.8 & 0.4 \\
Acids and esters & 4.7 & 6.2 \\
Unidentified & 45.1 & 10.4 \\
Total & & 100 \\
\hline
\end{tabular}




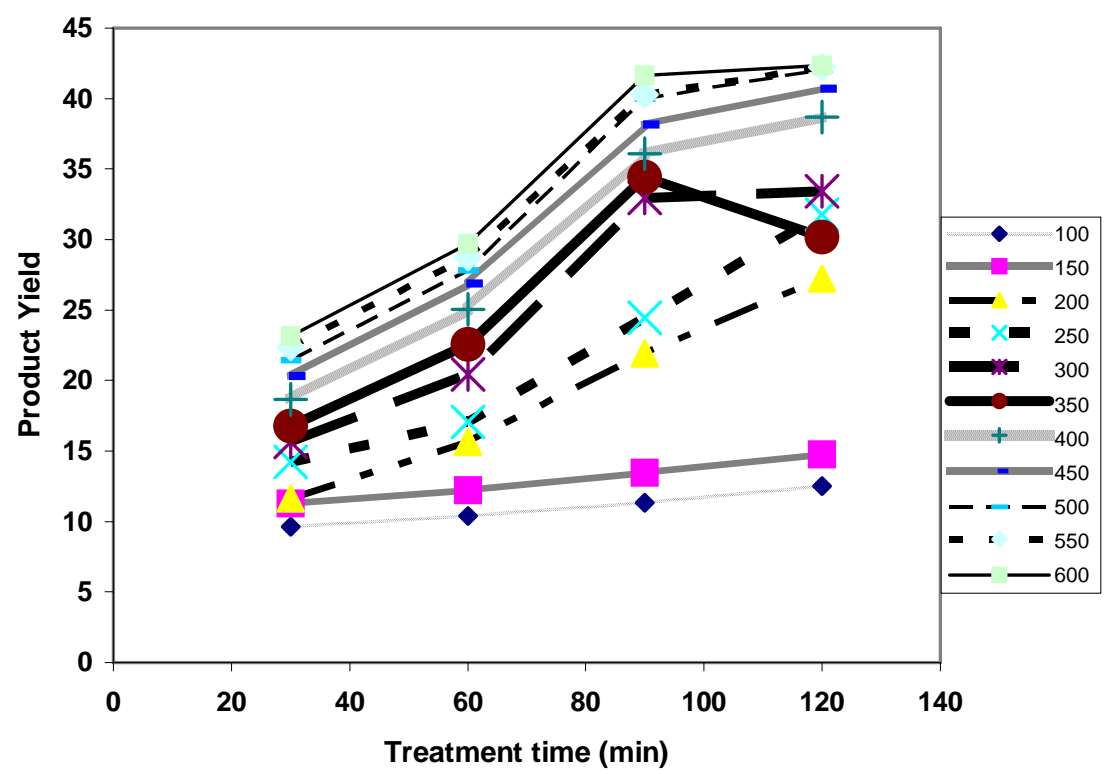

Figure 2: Effect of treatment time and temperature on product yield

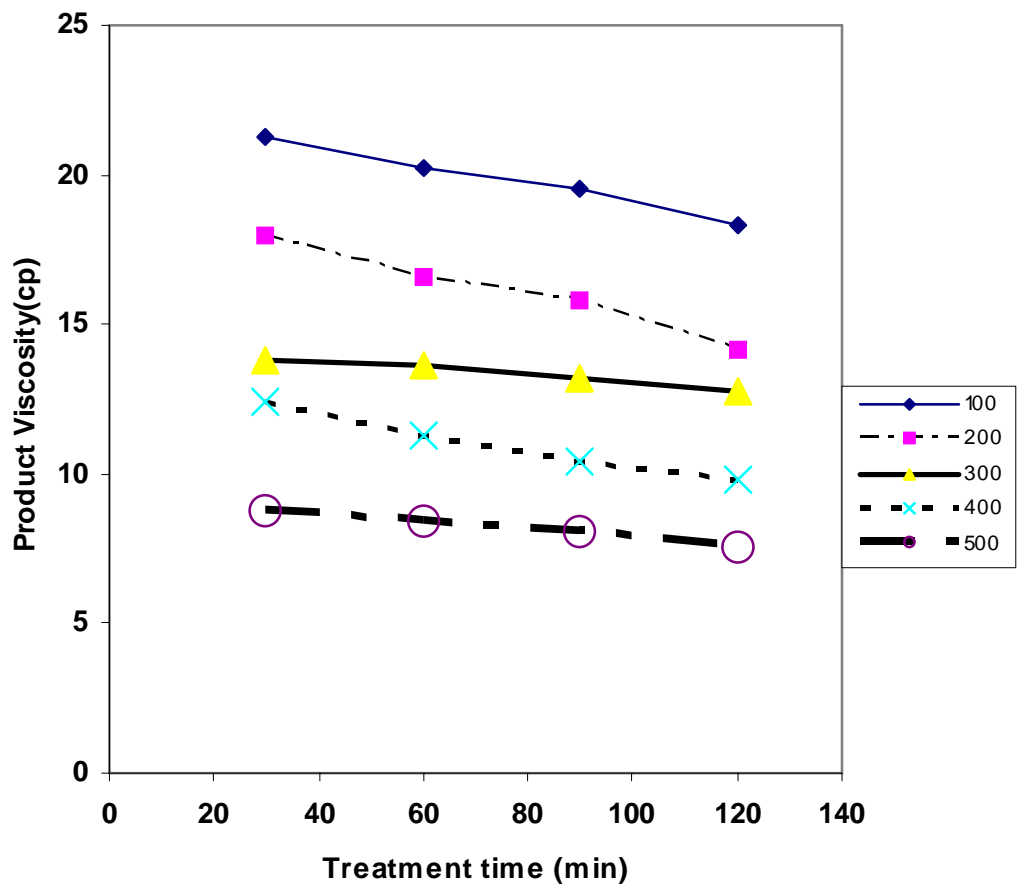

Figure 3: Effect of treatment time and temperature on product viscosity. 


\section{Effects of Additive System and Additive-to- residue ratio on Product Characteristics and Reaction Kinetics}

The relative proportions of the products spectrum obtained from with the use of methanol and methanolic potassium hydroxide mixture at various solvent-to-residue ratios used are as shown in Table 4. For the two additive systems, the percentage of the aromatic compounds increase with increasing ARR. However, the percentage is higher at every stage obtained with methanolic potassium hydroxide mixture than in the methanol system. This may be due to the fact that these chemicals had undergone cracking reaction involving rupture of carbon-carbon bonds yielding lighter hydrocarbons However, since an aliphatic content of less than $40.0 \mathrm{wt} \%$ was reported for the petroleum residue used [Bello, et. al., 2001], the trend should be attributable to methanol enhancing effect involving the capture of carbon species by free radical created during the delayed coking reaction. The high yield of aliphatic hydrocarbons in the presence of methanol and potassium hydroxide strongly indicate these additives to be promoters of the cracking reaction. This might be due to the fact that there was increased reaction due to addition of methanolic potassium hydroxide aiding decomposition of petroleum residue sample.

It might also be due to the fact that alcohol and potassium hydroxide provide the opportunity for chemical reaction during the conversion because of the nucleophilicity of the alcohol hydroxyl group and the tendency of the alcohol to act as a hydrogen donor. It is thought that such methanol enhancing effect may involve the capture of carbon species by free radial created during the delayed coking cracking reaction. This results in the return of more cracked liquid reactant fraction to the vapor phase. Thus, the methanol gives a higher percentage of aromatic hydrocarbons than methanolic potassium hydroxide, probably due to its greater selectivity towards aromatics. The results of feed conversion and distillate yields as functions feed properties, varied methanol and potassium hydroxide concentrations and ARR at reactions temperatures and time of $400^{\circ} \mathrm{C}$ and 120 minutes respectively are as presented in Table 4 .
In the absence of methanol the yield of coker distillate increased as coking temperature was increased from $100^{\circ \mathrm{C}}$ to $500^{\circ} \mathrm{C}$, at $250^{\circ} \mathrm{C}$ no appreciable change in the yield of coker distillate was observed for petroleum residue samples containing up to 5 percent methanol.

Figures 4 shows the result of kinetic analysis of the process reaction, with the conversion for given reaction temperatures and concentrations plotted as a functions of time. The degree of the conversion reaction was observed to depend on the reaction concentration and temperature. The higher conversion from the progress of reaction plots is that observed when $24 \%$ methanol was added. Figure 4 also shows the effect of initial concentration of methanol on the rate of conversion of the petroleum residue to hydrocarbons. As can be seen, the methanol has relatively high effect on the overall conversion process. It is thought that such methanol enhancing effect may involve the capture of carbon species by free radical created during the delayed coking reaction. This results in the return of more cracked liquid reactant fraction to the vapor phase. The reaction rate data obtained in this study were analyzed using first-order reaction model. This model is the one which best fits the result of previous workers for the kinetics of heavy oil conversion process. The present study confirms this mechanism. Arrhenius plots for the rate constants obtained from the least-square regression applied to the database is shown in Figure 4. Activation energy of $24.5 \mathrm{Kcal} / \mathrm{mol}$ was obtained. Efficiency of the petroleum residues thermal process increase with the increase in temperature and initial potassium hydroxide concentration. A conversion process efficiency of $70 \%$ was achieved at operating temperature of $500^{\circ} \mathrm{C}, 24 \%$ methanol and $0.6 \mathrm{M}$ potassium hydroxide. On the basis of the kinetic studies and result presented the knowledge of the conversion kinetic will facilitate the design of efficiently operating delayed coking batch reactor. Also, limitation in the equipment used in this study did not allow carrying out the process under continuous conditions. Such work should be undertaken if the process is to be fully evaluated for possible industrial application of petroleum residues thermal conversion process. 


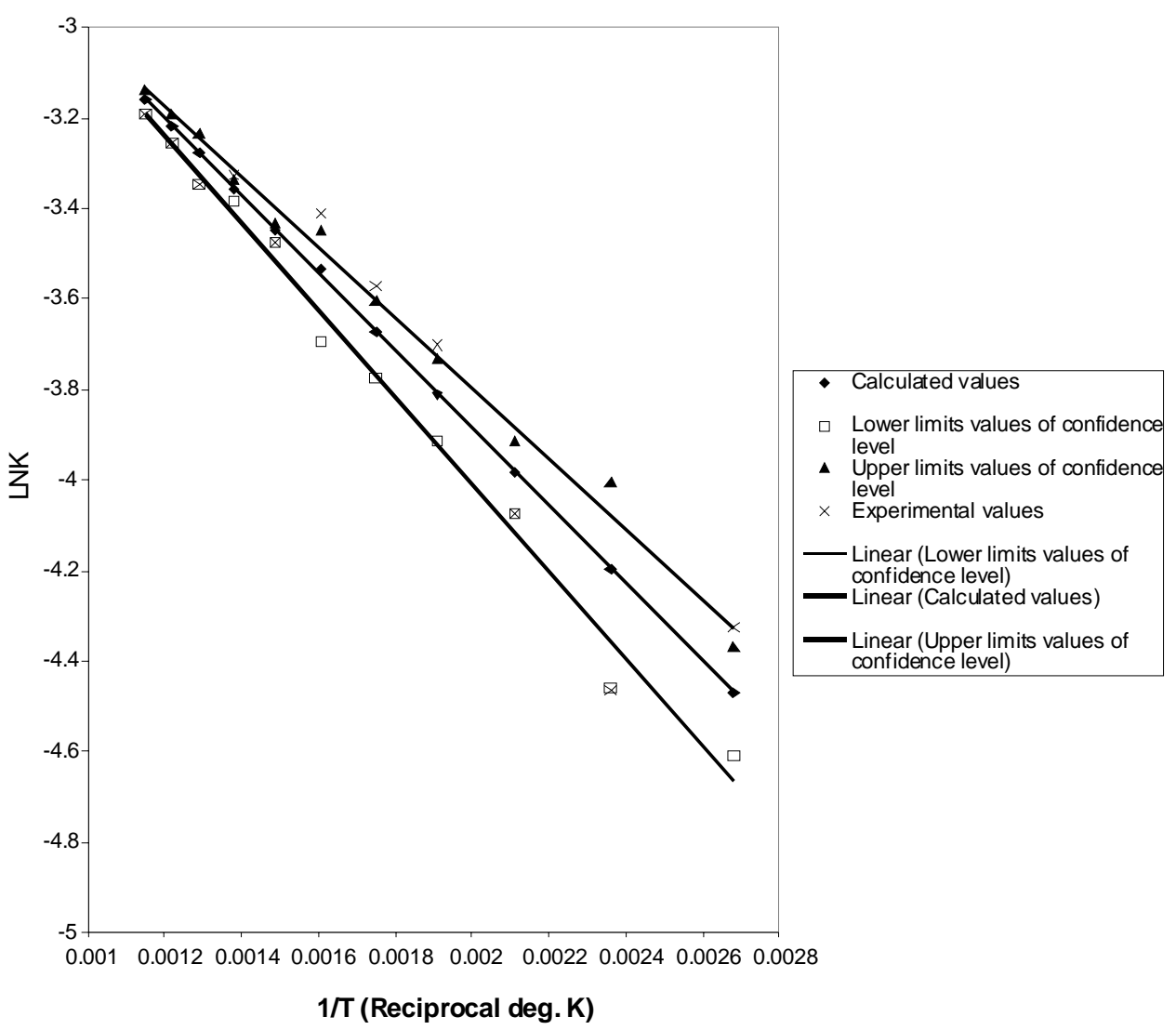

Figure 4: Arrhenius plot for the constant of model equation at $24 \% \mathrm{~V} / \mathrm{V} \mathrm{Me} \mathrm{OH}+0.6 \mathrm{M} \mathrm{KOH}$

\section{CONCLUSIONS}

The exploratory study of upgrading Nigerian petroleum residue in a delayed coking reaction system has indicated that it is practical to produce high quality liquid products by delayed coking of the petroleum residue at high temperature and low pressure with chemical additives. Results obtained from the experimental work shows that operating temperature, residence time, additive concentration loading and additive-to-residue ratio have important influence on the efficiency of petroleum residue to fuels and chemicals. The OLP and aromatic hydrocarbon selectivities followed the order methanolic potassium hydroxide $>$ methanol $>$ no additive. High OLD and aromatic hydrocarbon selective for methanol - potassium hydroxide were due to methanol enhancing effect involving the capture of carbon species by free radical created during the delayed coking reaction.

The OLP yield was maximum at $350^{\circ} \mathrm{C}$ and a maximum fraction of $83 \mathrm{wt} \%$ of OLP consisted of aromatic hydrocarbons using two methanol- potassium hydroxide at optimum reaction temperature and a residence time of 2 hours. The OLP obtained without methanol additive consisted of a higher fraction of aliphatic hydrocarbons whereas that with methanol-potassium hydroxide mixture contained more aromatic hydrocarbons. The OLP yield was approximately $1 / 4$ of the petroleum residue with $83 \mathrm{wt} \%$ selectively for aromatic hydrocarbons. Higher residence time was desirable for high OLP yield in all the three thermal conversion cases. Therefore, it is recommended that an evaluation of this process under continuous mode may be performed.

\section{REFERENCES}

Bello, O. O., Macaulay, S. R. A., Layokun, S. K. and Ademodi, B., Synthetic Fuel Production from the Nigerian Refinery Fuel Vacuum residues. African Journal of Science and Technology. Vol. 2 (No. 1 and 2), pp. 208-212 (2001).

Ukwuoma, O., The Production of Synthetic Fuels from Nigeria Tar sand bitumen. Fuel Science and 
Technology International, Vol. 11 (No. 11), pp. 1629 (1993).

Bonila, J. A., Delayed Coking and Solvent Deasphalting: Options for Residue Upgrading. A.I.Ch.E. National Meeting, Anaheim, California, USA, June (1982).

Jiazhi, X., Lanjuan, W., Qinglin, C. and Daoming, W., Modeling for Product Distribution in Thermal Conversion of Heavy oil. Petroleum Science and Technology, Vol. 20 (No. 5 \& 6) pp. 605-612 (2002a).

Jiazhi, X., Lanjuan, W., Qinglin, C. and Antai, S., Experimental Verification for Process Modelling of Coking Heater Inner Tube, Petroleum Science and Technology, Vol. 20 (No. 5 \& 6) pp. 613-620 (2002b).

Elliott, J. D., Godino, R.L. and McGrath, M. J., NonCatalytical Heavy Crude Upgrading. Third UNITAR Conference on Heavy Crude and Tar sands, pp. 1147-1156 (1981).

Schucker, R. C., Thermo gravimetric Determination of the Coking Kinetics of Arabian Heavy Vacuum Residuum. I\&EC Process Design and Development, Vol. 22, pp. 615 (1983).

Zacheria, M. G., Linda, G. S. and Michael, A. K. Heavy Oil Upgrading. Journal of Petroleum Technology, pp. 1024-1036 (1982). 